\title{
GALERI ANIMASI DI BANJARBARU
}

\author{
Muhammad Rizali \\ Program Studi Teknik Arsitektur Fakultas Teknik Universitas Lambung Mangkurat \\ m.rizali.y@gmail.com
}

\author{
Nurfansyah \\ Program Studi Teknik Arsitektur Fakultas Teknik Universitas Lambung Mangkurat \\ nfsarsitek@ulm.ac.id
}

\begin{abstract}
ABSTRAK
Perkembangan animasi semakin pesat setiap tahunnya, penggunaan animasi saat ini sudah mencakup ke seluruh bidang, mulai dari dunia hiburan hingga ke dunia bisnis. Tujuan perancangan Galeri Animasi ini adalah untuk lebih memperkenalkan animasi kepada masyarakat. Galeri Animasi akan dirancang dengan menggunakan metode analogi serta bertema Arsitektur Hi-Tech. Animasi dianalogikan ke dalam sebuah desain arsitektur dengan cara meminjam prinsip pergerakan dalam animasi itu sendiri, yaitu bagaimana tahapan suatu objek bergerak dalam sebuah animasi. secara umum, pergerakan di dalam animasi bekerja dengan 2 unsur yaitu keyframe dan in-between. Jika dalam arsitektur keyframe diibaratkan sebagai sebuah ruang dan in-between sebagai sirkulasi.

Kata kunci: Galeri Animasi, Analogi, Keyframe, In-Between.a, kunci, abstrak.
\end{abstract}

\section{ABSTRACT}

The development of animation is growing rapidly every year, the use of animation which currently covers all fields, ranging from the world of entertainment to the world of business. The purpose of designing this Animation Gallery is to further introduce animation to the public. Animation Gallery will be designed using analogy methods and themed Hi-Tech Architecture. Animation is analogous to an architectural design by borrowing the principle of movement in the animation itself, namely how the stages of an object moving in an animation. Generally, movement in animation works with 2 elements, namely keyframe and in-between. If in architecture the keyframe is compared as a space and in-between as a circulation.

Keywords: Animation Gallery, Analogy, Keyframe, In-Between.

\section{PENDAHULUAN}

tahunnya, penggunaan animasi saat ini sudah mencakup ke seluruh bidang, mulai dari dunia hiburan sampai ke dunia bisnis. Hal ini membuat industri dunia animasi tidak akan pernah sepi seiring berkembangnya teknologi digital.
Di berbagai negara maju maupun negara berkembang, penggunaan animasi sudah merambah ke dunia yang lebih luas sepeti dunia hiburan dan dunia bisnis. Berdasarkan fenomena yang ada, diketahui bahwa industri animasi mempunyai potensi yang besar di Indonesia. Akan tetapi, potensi ini tidak diiringi dengan minat 
masyarakat terhadap animasi sehingga menyebabkan kurangnya animator di Indonesia. Kurangnya animator di bidang animasi ini dilihat dari sedikitnya pelaku usaha di bidang tersebut.

Selain itu, subsektor animasi pada ekonomi kreatif Indonesia memiliki pelaku usaha yang termasuk sedikit. Di pulau Kalimantan sendiri hanya terdapat 119 pelaku usaha di bidang animasi, bahkan di kota Banjarbaru belum terdapat pelaku usaha animasi yang resmi maupun studio animasi yang mampu menampung animator-animator lokal, padahal di kota Banjarbaru setidaknya 4 Sekolah Menengah Kejuruan terdapat jurusan yang berhubungan dengan animasi seperti jurusan multimedia dan desain komunikasi visual serta dua di antara sekolah tersebut pernah menjuarai Lomba Kompetensi Siswa tingkat Provinsi Kalimantan Selatan di bidang animasi. Meskipun demikian, masih banyak masyarakat yang belum mengetahui akan bakat dan karya mereka.

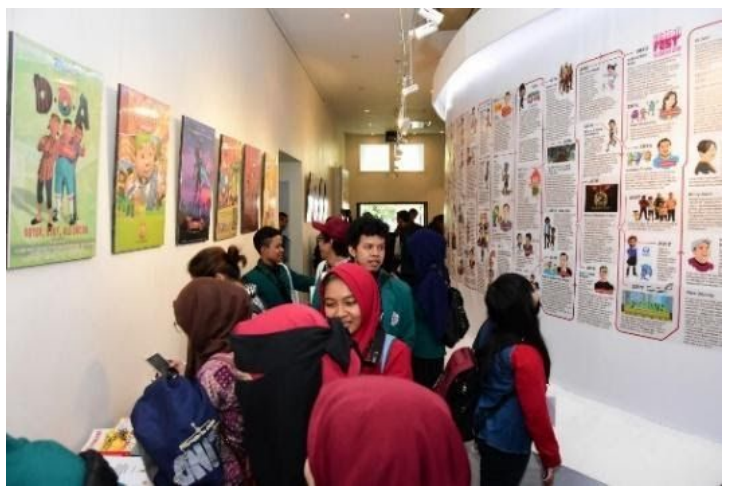

Gambar 1. Kegiatan Animakini X Ciffest 2018

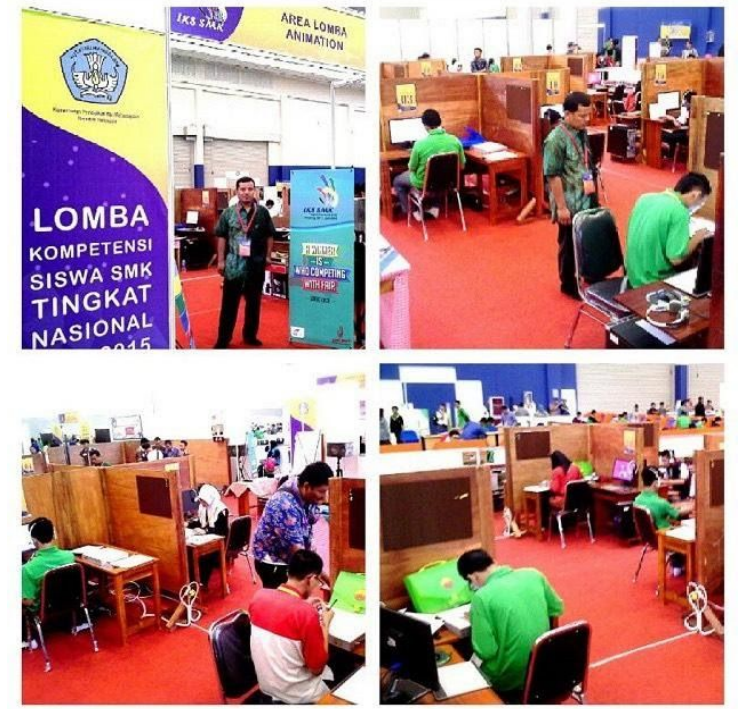

Gambar 2. Lomba Kompetensi Siswa SMK Nasional 2015 Bidang Animasi

Oleh karena itu, demi meningkatkan kualitas ekonomi kreatif di bidang animasi Indonesia khususnya di Banjarbaru serta dalam rangka memanfaatkan potensi industri animasi yang ada maka diperlukanlah sebuah rancangan galeri animasi yang dapat menjadi sarana edukasi dan informasi sekaligus rekreasi bagi masyarakat agar lebih mengenal animasi lebih jauh dan diharapkan tertarik akan dunia peranimasian sehingga dapat menghasilkan sumber daya manusia yang berbakat di bidang tersebut, serta menjadi wadah bagi animator-animator lokal untuk berkarya dan menunjukkan hasil karya mereka.

\section{PERMASALAHAN}

Bagaimana rancangan Galeri Animasi yang dapat menjadi wadah kreasi dan apresiasi untuk animator lokal serta memiliki daya tarik yang kuat untuk masyarakat agar belajar animasi sehingga dapat membantu meningkatkan potensi ekonomi kreatif di Banjarbaru khususnya di bidang animasi? 


\section{TINJAUAN PUSTAKA}

\section{A. Pengertian Animasi}

Animasi dapat diartikan sebagai gambar yang seakan-akan bergerak, karena kemampuan otak untuk selalu mengingat gambar-gambar yang ditangkap oleh mata secara terus-menerus. Animasi juga merupakan kegiatan menghidupkan sebuah cerita dari beberapa gambar yang berkesinambungan sehingga ketika dalam proses animasi gambar tersebut terlihat seperti hidup (Pamungkas, 2011:4).

Bagaimana caranya agar animasi bisa dinikmati? Caranya adalah dengan menggunakan sekumpulan gambar yang berubah sedikit demi sedikit, kemudian ditampilkan secara bergantian dan berurutan dengan kecepatan tertentu, sehingga menghasilkan kesan sebuah gambar yang bergerak.

\section{B. Jenis-Jenis Animasi}

Secara garis besar, ada beberapa jenis animasi yaitu, animasi dua dimensi yang biasanya dibuat dengan cara tradisional, kemudian animasi tiga dimensi yang dibuat menggunakan bantuan komputer serta animasi stop motion.

\section{Tinjauan Arsitektur High Tech}

Ada 6 hal penting yang menjadi ciri dari arsitektur high tech menurut Charles Jenks, yaitu:

1. Bagian dalam bangunan yang Diperlihatkan ke luar. Pada bangunan dengan arsitektur hi-tech, saluran-saluran utilitas maupun strukturnya diperlihatkan ke luar dan dijadikan sebagai fasad eksterior.

2. Kebanggan akan sebuah proses. Desain bangunan dengan konsep arsitektur hi-tech biasanya terkesan seperti tidak selesai atau seperti kumpulan struktur-struktur yang terlihat.

3. Transparansi. Bangunan dengan konsep arsitektur hi-tech biasanya menggunakan material dinding yang transparan seperti kaca.

4. Pewarnaan yang cerah. Penggunaan warna yang cerah pada arsitektur hi-tech disini ditujukan sebagai pembeda antara struktur dan utilitas yang terlihat dari luar.

5. Menggunakan struktur tambahan sebagai penguat. Bangunan dengan arsitektur hi-tech mempunyai struktur kolom kecil yang menyilang sebagai penguat struktur utama bangunan.

6. Mengikuti perkembangan zaman. Penggunaan arsitektur hi-tech pada sebuah bangunan merupakan sebuah sikap percaya terhadap 7. perkembangan zaman.

\section{METODE PERANCANGAN}

\section{A. Metode Arsitektur Analogi}

Analogi adalah Sebuah metode untuk mengambil sistem yang ada pada sebuah benda. Ada beberapa jenis analogi yaitu, analogi personal, analogi langsung dan analogi simbolik. Pada rancangan galeri animasi ini menggunakan metode analogi langsung dimana prinsip sebuah animasi diterapkan sebagai dasar dari konsep perancangan galeri animasi ini.

\section{PEMBAHASAN}

\section{A. Konsep Programatik}

Pada perancangan Galeri Animasi di Banjarbaru ini menerapkan konsep program dari Analogi animasi. Animasi itu sendiri memiliki makna menghidupkan atau seakan-akan hidup, makna tersebut diterapkan dengan prinsip pergerakan animasi yang terdiri dari 2 hal penting yaitu keyframe dan in-between. Keyframe awal diisi dengan keinginan yang dapat menghidupkan. Sedangkan in-between diisi dengan elemen visual sebagai perantara 
dalam mewujudkan hasil yang berupa interaksi (keyframe akhir).

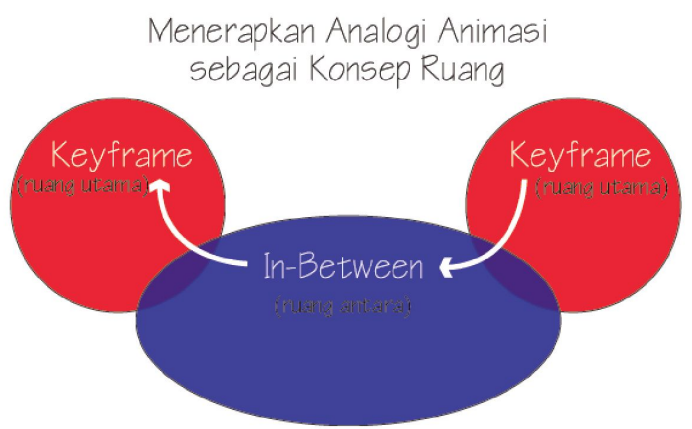

Gambar 3. Analogi Animasi sebagai Konsep

\section{Ruang}

Konsep analogi animasi ini kemudian digunakan sebagai dasar penyusunan tata massa bangunan pada tapak serta layout ruang pada bangunan utama galeri animasi.

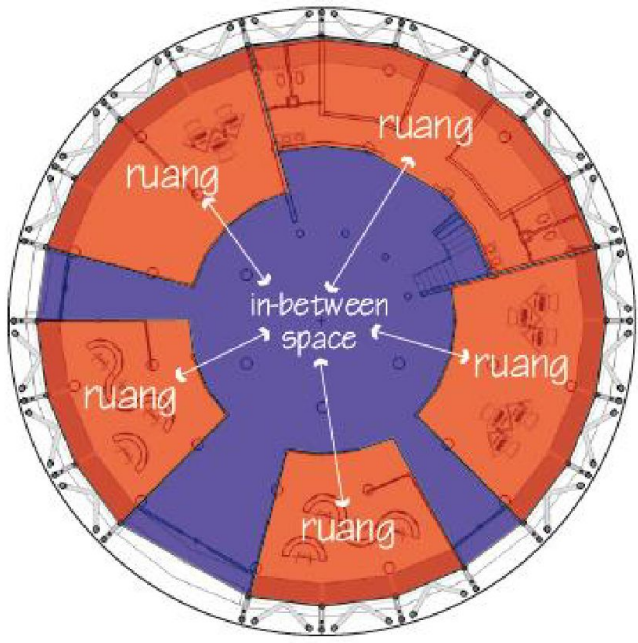

$$
\begin{gathered}
\text { Konsep analogi animasi } \\
\text { yang diterapkan } \\
\text { di dalam bangunan, } \\
\text { menciptakan } \\
\text { hubungan antar ruang } \\
\text { dalam bangunan }
\end{gathered}
$$

Gambar 4. Penerapan Analogi Animasi ke dalam Sistem Ruang

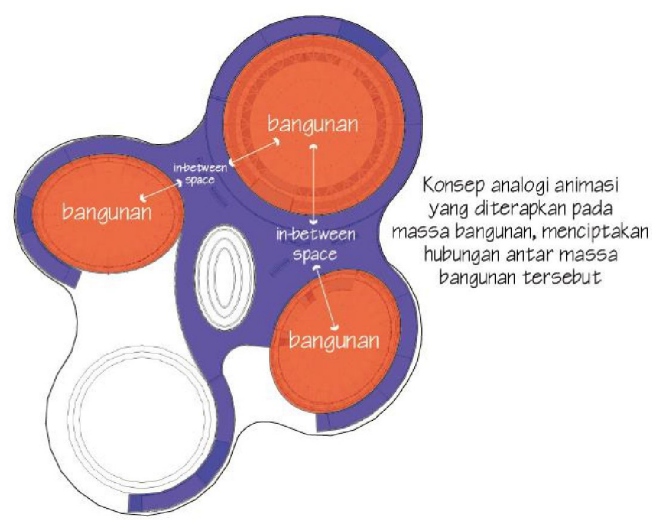

Gambar 5. Penerapan Analogi Animasi ke dalam Tata Massa Bangunan

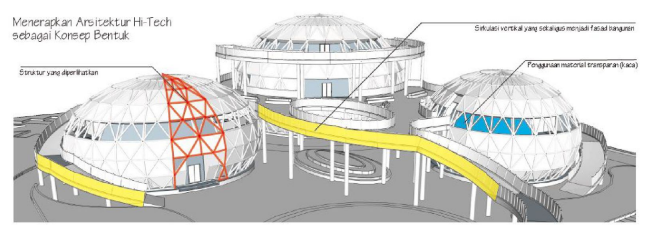

Gambar 6. Penerapan Arsitektur Hi-Tech sebagai Konsep Bentuk Bangunan

Pada rancangan Galeri Animasi ini menerapkan konsep bentuk Arsitektur Hi-Tech selaras dengan makna animasi itu sendiri yang merupakan hasil dari sebuah perkembangan teknologi

\section{B. Konsep Ruang}

Penerapan Konsep Analogi Animasi terhadap sistem ruang menghasilkan pembagian zona ruang tiap lantai berdasarkan fungsi dan sifat ruangnya. 


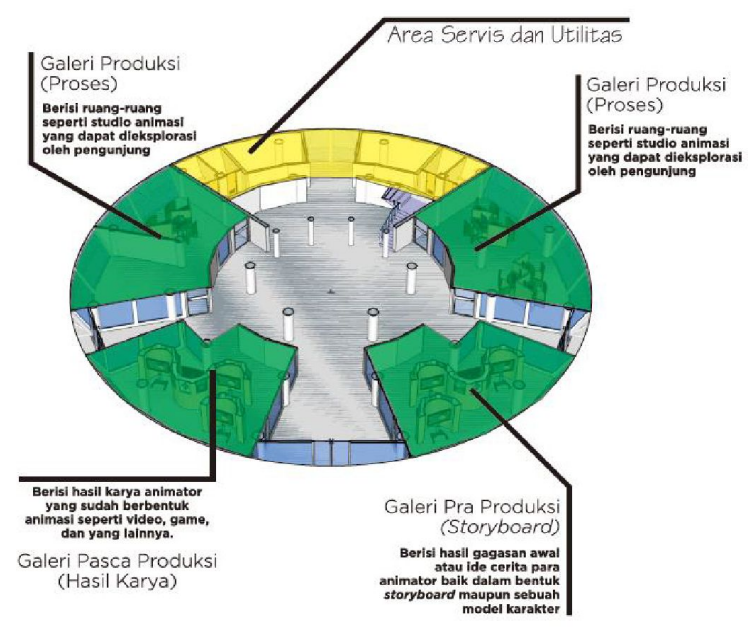

Gambar 7. Sistem Ruang Galeri Animasi (Zona Eksibisi)

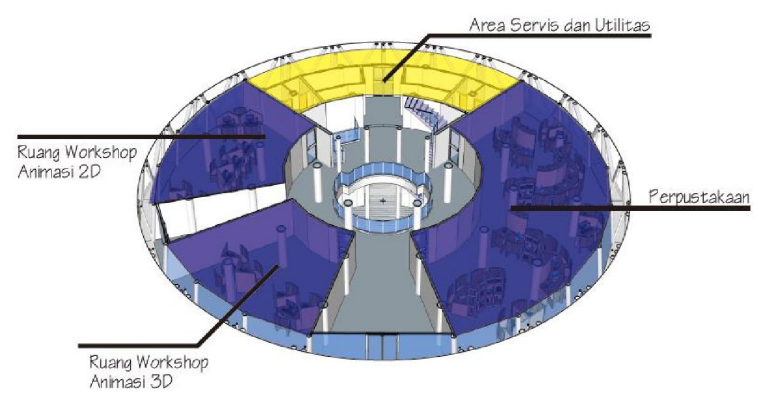

Gambar 8. Sistem Ruang Galeri Animasi (Zona Edukasi)

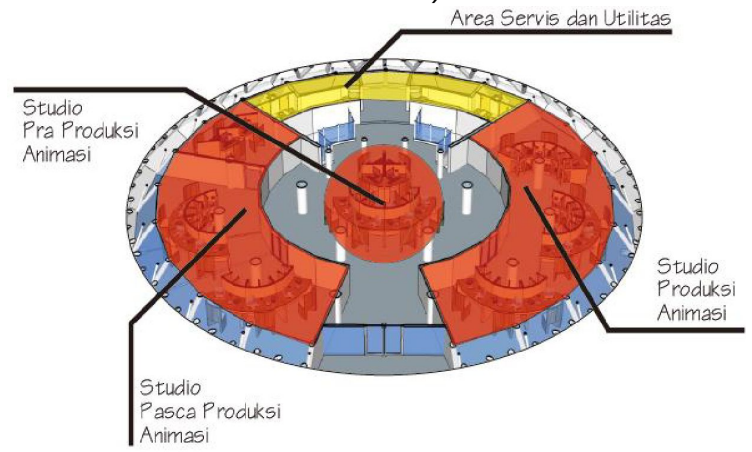

Gambar 9. Sistem Ruang Galeri Animasi (Zona Produksi)

\section{Hasil Rancangan}

Berdasarkan penerapan konsep analogi pada tata massa bangunan dihasilkan rencana tapak seperti gambar dibawah, Galeri Animasi terdiri dari 3 massa bangunan, satu bangunan utama yang berbentuk lingkaran dan dua bangunan pendukung yang berbentuk elips.

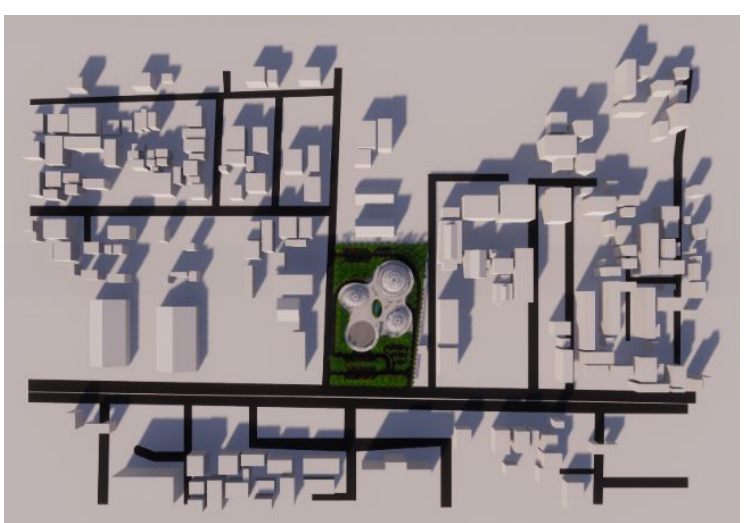

Gambar 10. Situasi Galeri Animasi

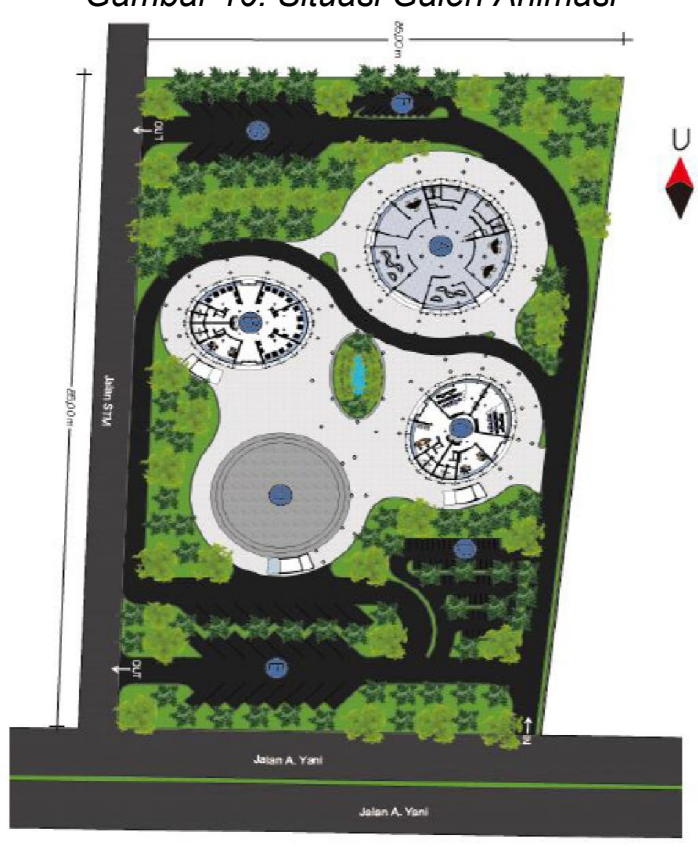

Gambar 11. Rencana Tapak Galeri Animasi 


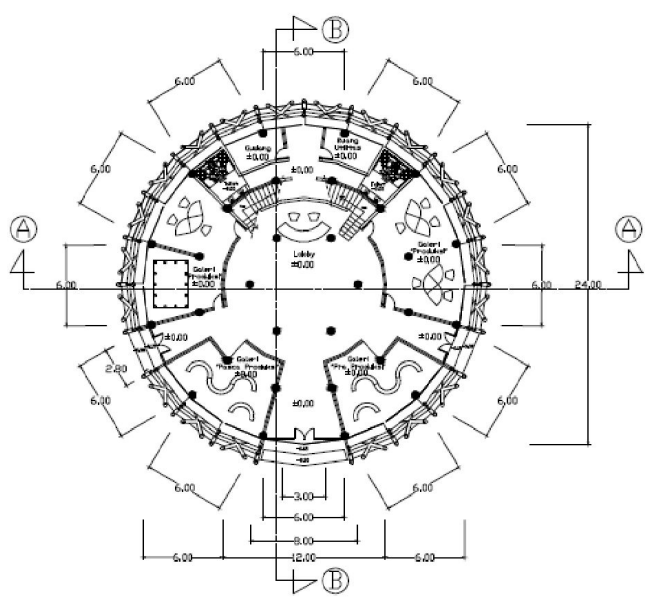

Gambar 12. Denah Zona Eksibisi Galeri Animasi

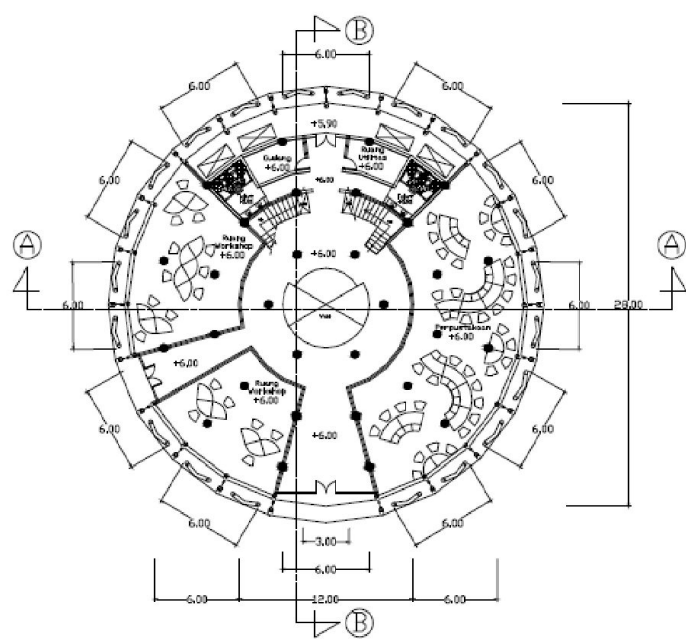

Gambar 13. Denah Zona Edukasi Galeri Animasi

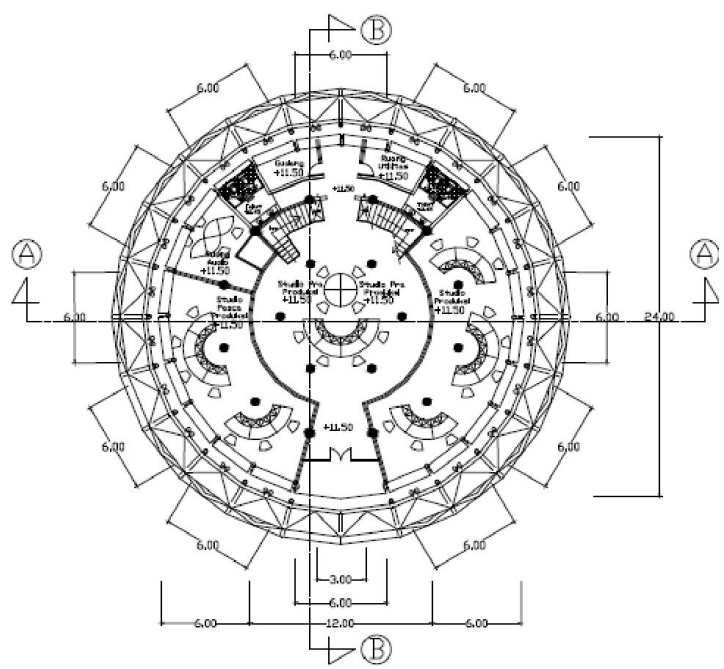

Gambar 14. Denah Zona Produksi Galeri Animasi

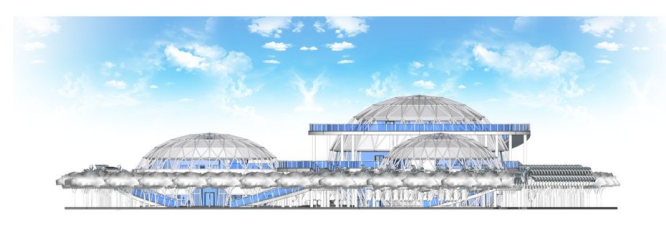

Gambar 15. Tampak Depan Kawasan Galeri Animasi

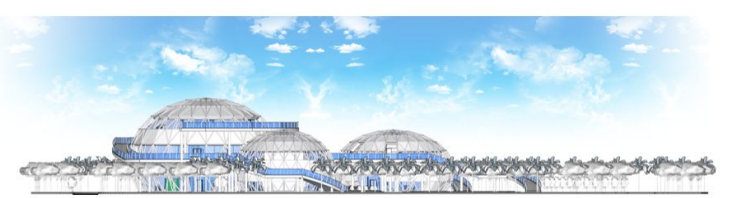

Gambar 16. Tampak Samping Kawasan Galeri Animasi

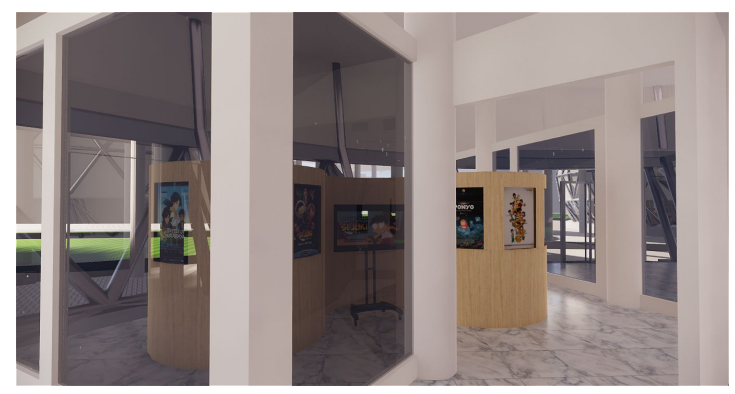

Gambar 17. Perspektif Interior Zona Eksibisi

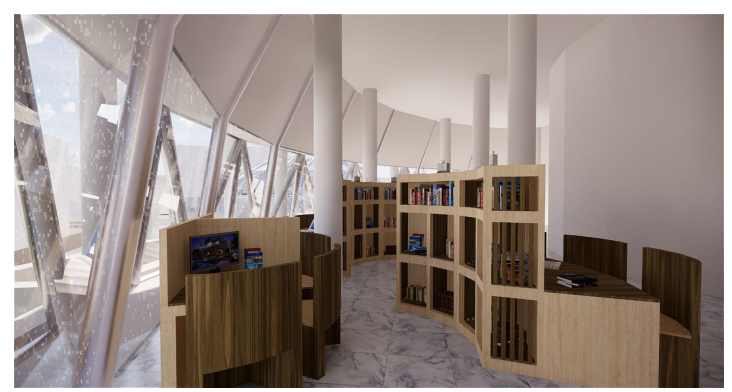

Gambar 18. Perspektif Interior Zona Edukasi

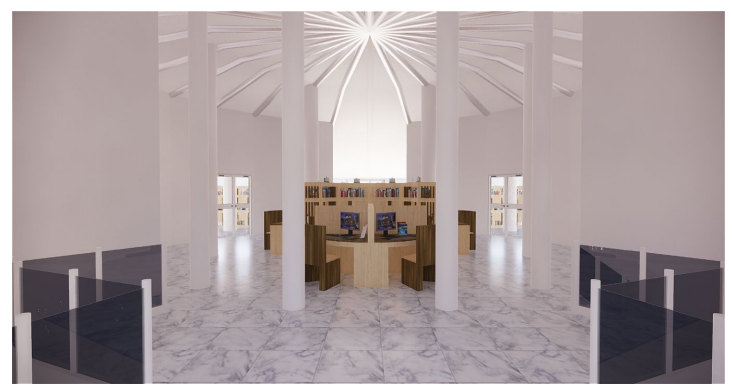

Gambar 19. Perspektif Interior Zona Produksi 

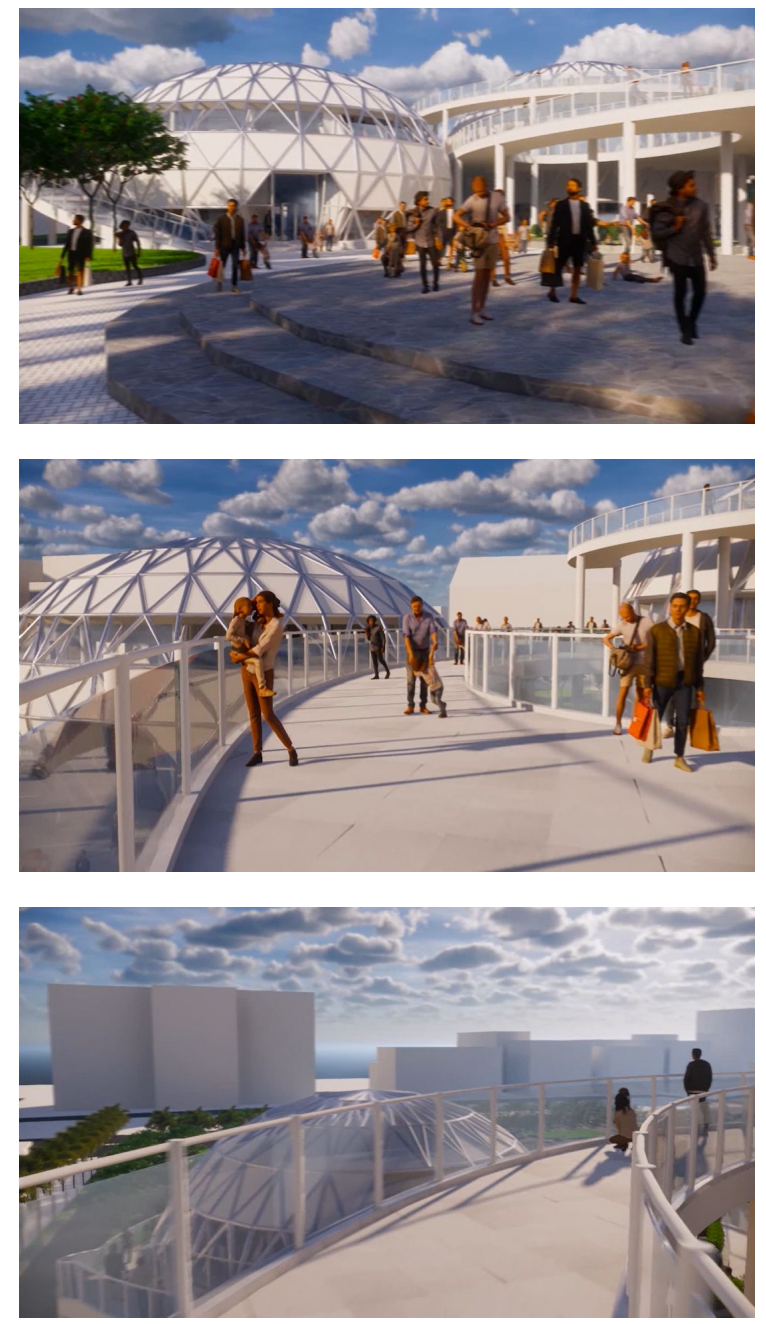

Gambar 20. Perspektif Eksterior Galeri Animasi

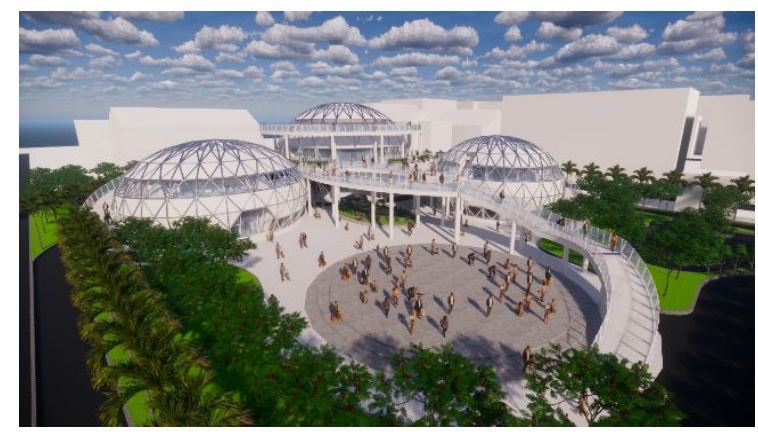

Gambar 21. Aerial View Kawasan Galeri Animasi

\section{KESIMPULAN}

Galeri Animasi merupakan sebuah tempat dimana para animator menghasilkan sebuah karya animasi yang nantinya akan ditampilkan ke masyarakat sehingga masyarakat lebih mengenal animasi maupun animator itu sendiri.

Desain galeri animasi ini dirancang dengan menggunakan metode analogi. Animasi dianalogikan ke dalam sebuah desain arsitektur dengan cara meminjam prinsip pergerakan dalam animasi itu sendiri, yaitu bagaimana tahapan suatu benda bergerak dalam sebuah animasi. secara garis besar, pergerakan animasi bekerja dengan 2 unsur yaitu keyframe dan in-between. jika dalam arsitektur keyframe diibaratkan sebagai sebuah ruang dan in-between sebagai sirkulasi.

Berdasarkan tujuan rancangan didapatkan 3 zona utama dalam galeri animasi yaitu zona eksibisi (publik), zona edukasi (semi-publik), dan zona produksi (privat). Galeri animasi ini juga menggunakan tema arsitektur hi-tech selaras dengan animasi yang juga merupakan sebuah perkembangan teknologi. Metode analogi digunakan untuk mendapatkan bentuk dasar bangunan yaitu lingkaran, sedangkan konsep arsitektur hi-tech digunakan dalam membuat massa bangunan galeri animasi itu sendiri dimana arsitektur hi-tech itu sendiri memiliki beberapa ciri diantaranya yaitu penggunaan material transparan, memperlihatkan struktur, dan menjadikan transportasi bangunan sebagai fasad.

Demikian konsep ini dipilih bertujuan untuk memperkenalkan animasi kepada masyarakat dengan tampilan yang lebih modern seiring perkembangan zaman serta diharapkan pula galeri animasi ini mampu 
mengubah mindset masyarakat tentang animasi yang hanya dianggap sebagai hiburan semata ataupun tontonan anak-anak, yang nyatanya animasi sekarang ini memiliki banyak kegunaan di berbagai macam bidang.

\section{DAFTAR PUSTAKA}

Davies, Colin. 1988. High Tech Architecture. New York. Rizzoli International Published Inc.

Nainggolan, B. 2014. Desain Interior Museum Kebudayaan Lampung di Karang, Bandar Lampung. S1 Thesis, 29-32.

Rochman, Faizal dkk. 2015. Rencana Pengembangan Animasi 2015-2019. Jakarta: PT. Republik Solusi.

Unwin, Simon. 1997. Analysing Architecture. London and New York. Routledge.

Vega, Wendi. 2004. The Making of Animation Homeland. Bandung: Megindo Tunggal Sejahtera.

Wright, Jean Ann. 2005. Animation Writing and Development. Amerika Serikat: Focal Press Publications. 